\title{
A geometric approach of working tool diameter in 3-axis ball-end milling
}

\author{
Balázs Mikó $^{1}$ - Péter Zentay ${ }^{2}$
}

Received: 5 February 2019 / Accepted: 30 May 2019 / Published online: 8 July 2019

(C) The Author(s) 2019

\begin{abstract}
When machining free-form surfaces with a ball-end milling tool, the working tool diameter is constantly changing even if the tool path is constant. The reason is that the surface normal of the milled surface is continuously changing along the milling path. When the working diameter is changing, the cutting parameters also change. This variation effects the roughness homogeneity of the smoothed surface. Simultaneous five-axis milling solves this problem; however, the price and complexity of this technology can be a problem for some industrial sectors. In the paper, the geometrical background of a solution to this problem is presented for a 3-axis ball-end milling process for machining a free form surface. The paper provides the deduction of the theory by the use of homogeneous transformations. The geometrical problem of the cutting process is treated locally where the general machined surface is substituted at every point by its tangent plane. From the result of the presented method, a milling strategy can be formulated for ball-end milling that minimises the change in the momentary working diameter thus providing a more constant cutting parameter.
\end{abstract}

Keywords Ball-end milling $\cdot$ Working diameter $\cdot$ Free-form milling $\cdot$ Inclined surface $\cdot$ CAM strategy $\cdot$ Surface quality

\section{Nomenclature}

D Tool diameter

$\mathrm{D}_{\text {eff }}$ Effective (working) tool diameter

$\mathrm{a}_{\mathrm{p}} \quad$ Step depth

$a_{e} \quad$ Step over parameter

$\mathrm{v}_{\mathrm{c}} \quad$ Cutting speed

$\mathrm{v}_{\mathrm{f}} \quad$ Feed speed

n $\quad$ Spindle speed

\section{Introduction}

The ball-end milling of free-form surfaces is one of the most often used technologies in the case of finishing. Basically, the revolving milling cutter follows the surface with a specific

Balázs Mikó

miko.balazs@bgk.uni-obuda.hu

1 Institute of Material and Manufacturing Science, Óbuda University, Népszínház u. 8, Budapest 1081, Hungary

2 Department of Manufacturing Science and Engineering, Budapest University of Technology and Economics, Müegyetem rkp. 3, Budapest 1111, Hungary speed (feed rate, $v_{f}$ ), and at the end of the surface, it steps aside and turns back. This strategy is suitable for prefinishing and finishing of non-undercut, shallow surfaces on a CNC milling machine. The strategy needs a CNC controller, and the CNC program can be generated by a CAM software based on the CAD model of the surface.

In the case of free-form surface milling with a ball-end milling cutter, the quality of surface roughness depends on several factors and parameters like the tool diameter, working diameter, cutting parameters, tool material, nature of the surface, tool path, milling direction etc.

Fan [1] investigates the changing of cutting speed in 3-axis ball-end milling and points out that the cutting speed is the speed factor that influences machined surface quality and tool life. de Souza et al. [2] show the effect of the working diameter in chip removal, cutting force and surface roughness, where higher cutting speed decreases the surface roughness. Wojciechowski et al. [3] analyses ball-end milling in the case of different tool inclination that results in different working diameters. In case of a large working diameter, the surface roughness is smaller, and the increasing cutting speed decreases the surface roughness quality.

Vopát et al. [4] present the effect of tool material and milling direction. The solid carbide end mill ensures better surface 
roughness and longer tool life than HSS Co, and in the case of both tool material, the down-milling results in better surface roughness. Wojciechowski et al. [5] present the dynamic model of ball-end milling, which can be a base of texture prognosis. Vyboishchik [6] presents a geometric model of surface topology in the case of a flat surface, a convex and a concave curved surface. Based on it, the inclination angle- the nature of the surface - has an important role.

Beno et al. [7] analyses the main features of free-form surfaces and proposes a process to identify the most suitable milling strategy. The paper concludes that cutting speed has main effect on surface quality beside other geometric and tool parameters. Pena et al. [8] present 5 different tool strategies and analyses them from the point of view of surface roughness in the case of 6061 aluminium. Due to different $R$ a parameters, a correction factor is introduced which modifies the feed rate in order to ensure better surface roughness. de Souza et al. [9] present the influence of the tool path strategy on surface quality. The different strategies result in different machining time and surface quality, which has an influence on the polishing time of the surface. The different path strategies result in different machining time as it was analysed by Sales et al. [10]. Ižol et al. [11] present the importance of milling strategies, where it is concluded that the applied strategies have larger effect on the surface roughness than the width of cut $\left(a_{\mathrm{e}}\right)$ " $r$ ". Pena et al. [12] investigate 6 different trajectories in the case of milling inclined surfaces. They found that the calculated cusp height is smaller than the real surface deviation and suggests correction coefficient to modify the width of the cut $\left(a_{e}\right)$. Redonnet et al. [13] present an optimisation of free-form surface machining direction with a torus end mill, minimising the machining time and considering the scallop height. Zhang et al. [14] present a geometric model for machined surface topography in a ball-end milling process, and based on this model, optimization for 3D arithmetic average deviation ( $S b a)$ and material removal rate (MRR) was developed. The effect of feed per tooth $\left(f_{z}\right)$ and the radial depth of cut $\left(a_{e}\right)$ were considered. In addition, vibration can also effect the surface topography [15].

The simultaneous 5-axis milling can solve the problem of varying working diameter; however, simultaneous 5-axis milling is a very complicated process, and the machine tool is much more expensive than the 3 -axis one.

In the industry, the most widely used process is the nonsimultaneous 5 -axis (or $3+2$-axis) milling for general machining, where the machining is done in three axes, and the positioning is made with the two indexing axes, (while machining is suspended). It is a more precise and simpler process than simultaneous 5-axis machining, and the machine tools and their controllers are easier to handle and program. These processes are widely used in engine block, gear block machining, or for manufacturing non-aerodynamics part of aircrafts. This is why the three-axis machining (mainly $3+2$-axis) in the mainstream industry will be an important process for a long time. This has been confirmed by serious industrial designers and manufacturers such as the development department of FFG MAG in Esslingen. Although the investigation of the paper is done for a 3-axis problem, it is still (and will be in the future) an important issue in the industry.

Xu et al. [16] developed a swept surface approach to model the topography of the machined surface in the case of ball-end milling. In the study, the ball-end cutter proceeds along a tool path in order to perform continuous material removal from the swept surfaces of the cutting edges. Liu et al. [17] present a method of surface segmentation in order to determine the best regions for a $3+2$-axis milling strategy, because static rotary axis allows higher feed rate.

The surface quality according to the geometrical model depends on the tool diameter $(D)$, the step over parameter $\left(a_{e}\right)$ and the inclination of the surface, also on the cutting parameters such as feed rate $\left(v_{f}\right)$ and cutting speed $\left(v_{c}\right)$. During the machining of free form surfaces, the inclination of the surface varies; therefore, the working diameter of the cutting tool is changing, thus the cutting speed also changes. The cutting speed defines the minimum value of the chip thickness. Based on our previous research ([18-20]), if the chip thickness is too small, because of small cutting speed, the tool cannot remove any material.

In this paper, the engineering aspects are highlighted, from the aspect of how the work of a CAM programmer can be supported. Previously, it was determined that beside other parameters, the cutting speed has an important effect on the surface roughness. In the case of ball-end milling, the working diameter can be a key element of the research.

The difference in our approach compared with the usual techniques is the pure geometric description of the working diameter. The developed mathematical model presents the milling of an inclined plane surface (with a ball-end cutter) (Fig. 1), where the tool paths are parallel to each other (Fig. 2).

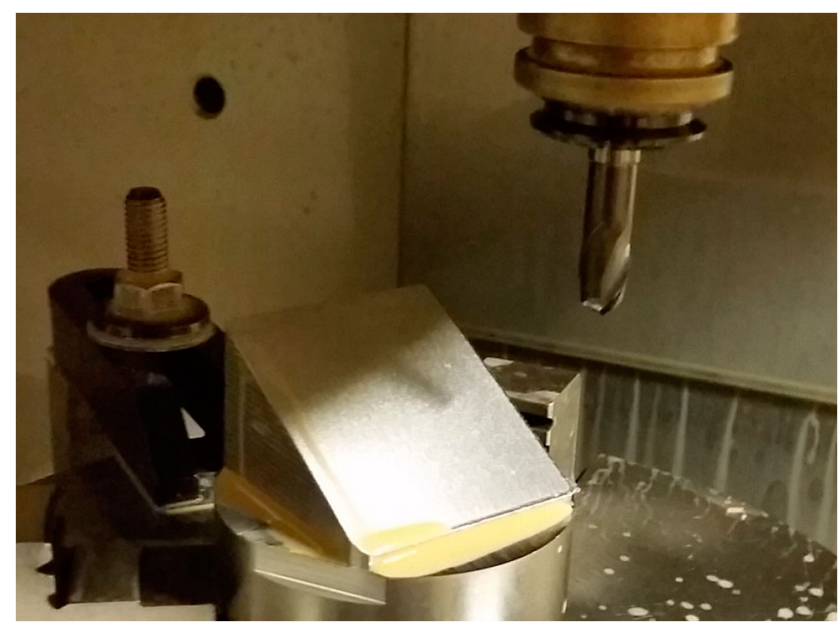

Fig. 1 Ball-end milling of an inclined test surface 


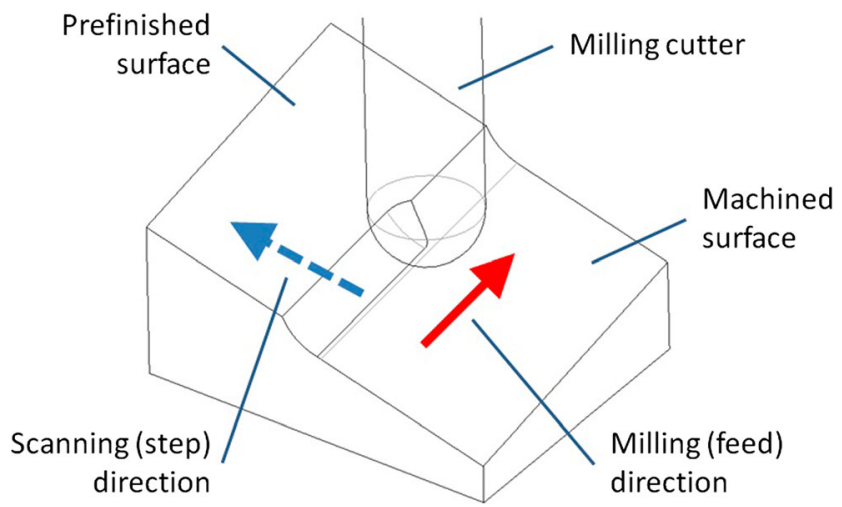

Fig. 2 Ball-end milling of an inclined plane surface

The inclined plane is a simplified model of the locality of a free-form surface. This plane can be considered as the tangent plane of the surface at the given point.

The simulation programming was performed in Maple software environment.

\section{Effective diameter}

Let the origin of the tool coordinate system be on the endpoint of the ball-end cutter, and the $z$-axis is parallel to the rotation axis of the tool. If $a_{\mathrm{p}}$ is the depth of cut and $D$ is the diameter of the cutting tool, the effective (working) diameter is (see: Fig. 3):

$D_{\text {eff }}=2 \cdot \sqrt{\left(\frac{D}{2}\right)^{2}-\left(\frac{D}{2}-a_{\mathrm{p}}\right)^{2}}$

$R_{\text {eff }}=\frac{D_{\text {eff }}}{2}$

The equation of the contact circle, which is the intersection of the ball-end cutter and the pre-finished surface is (represented in homogenous coordinates):

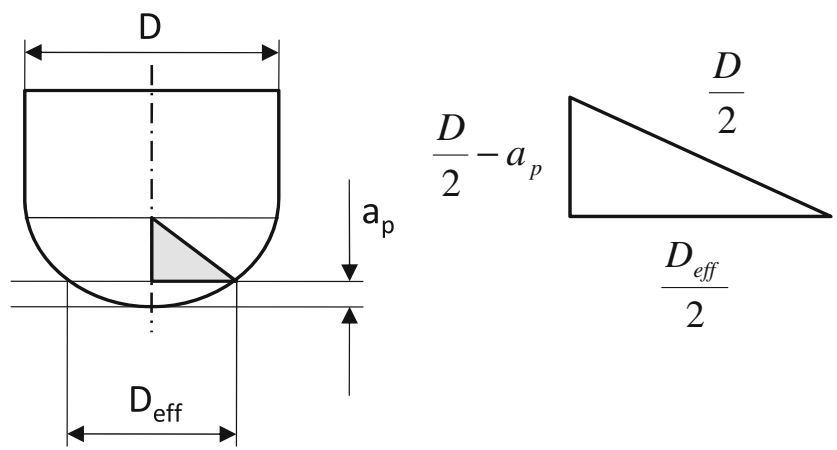

Fig. 3 Definition of the effective diameter in the case of a horizontal plane
$\underline{\mathrm{Cr}}_{\mathrm{eff}}=\left[\begin{array}{c}R_{\mathrm{eff}} \cdot \cos (2 \pi \mathrm{t}) \\ R_{\mathrm{eff}} \cdot \sin (2 \pi \mathrm{t}) \\ \mathrm{a}_{\mathrm{p}} \\ 1\end{array}\right], t \in[0,1]$

According to the changing of the inclination of the milled plane, this circle keeps its shape and parallel position to the plane (if the curvature of the surface is much smaller than the diameter of the tool). Nevertheless, the position and the effective diameter of the circle change related to the axis of the tool.

General position of the surface and the tool can be described by the contact point (see. Fig. 4). Let the contact point between the tool and the surface in a general case be $P_{t}$ :

$\underline{P}_{t}=\left[\begin{array}{c}x_{\mathrm{t}} \\ y_{\mathrm{t}} \\ z_{\mathrm{t}} \\ 1\end{array}\right]$

and the surface normal vector be $N$ :

$\underline{N}=\left[\begin{array}{c}x_{\mathrm{N}} \\ y_{\mathrm{N}} \\ z_{\mathrm{N}} \\ 1\end{array}\right]$

The contact point $\left(P_{t}\right)$ and the origin of the tool coordinate system $\left(O_{t}\right)$ coincide only if the milled surface is perpendicular to the axis of the tool. However, in the general case, a geometrical transformation is needed to identity position. Two rotational transformations are needed to determine the two points. The two angles of the transformation are determined relative to the surface normal vector (Fig. 5), where the axes $(x, y, z)$ refer to the workpiece frame:

$\operatorname{tg} \mathrm{A}_{\mathrm{N} 1}=\frac{\mathrm{y}_{\mathrm{N}}}{\mathrm{x}_{\mathrm{N}}} \rightarrow A_{\mathrm{N} 1}=\operatorname{arctg}\left(\frac{\mathrm{y}_{\mathrm{N}}}{\mathrm{x}_{\mathrm{N}}}\right)$
$\cos \mathrm{A}_{\mathrm{N} 2}=\frac{\mathrm{z}_{\mathrm{N}}}{1} \rightarrow A_{\mathrm{N} 2}=\arccos \left(\mathrm{z}_{\mathrm{N}}\right)$

The transformation process is the following:

1. Rotation with the angle $A_{\mathrm{N} 2}$ around the axis, which is parallel to the $y$-axis and passes through the centre point $\left(C_{\mathrm{P}}\right.$ on Fig. 4$)$ of the tool:

a. Linear translation to the centre $\left(\underline{T}_{1}\right)$

b. Rotation around $y$-axis with $\mathrm{A}_{\mathrm{N} 2}\left(\underline{F}_{1}\right)$

c. Reverse linear translation $\left(\underline{T}_{2}\right)$

2. Rotation around $z$-axis with $\left.A_{\mathrm{N} 1} \stackrel{\underline{\underline{F}}}{\underline{\underline{F}}}\right)$

The transformation is performed by the following matrix (see details in Appendix 1, Eq. 15-31): 
Fig. 4 Contact point $\left(P_{\mathrm{t}}\right)$ and the transformed plane surface
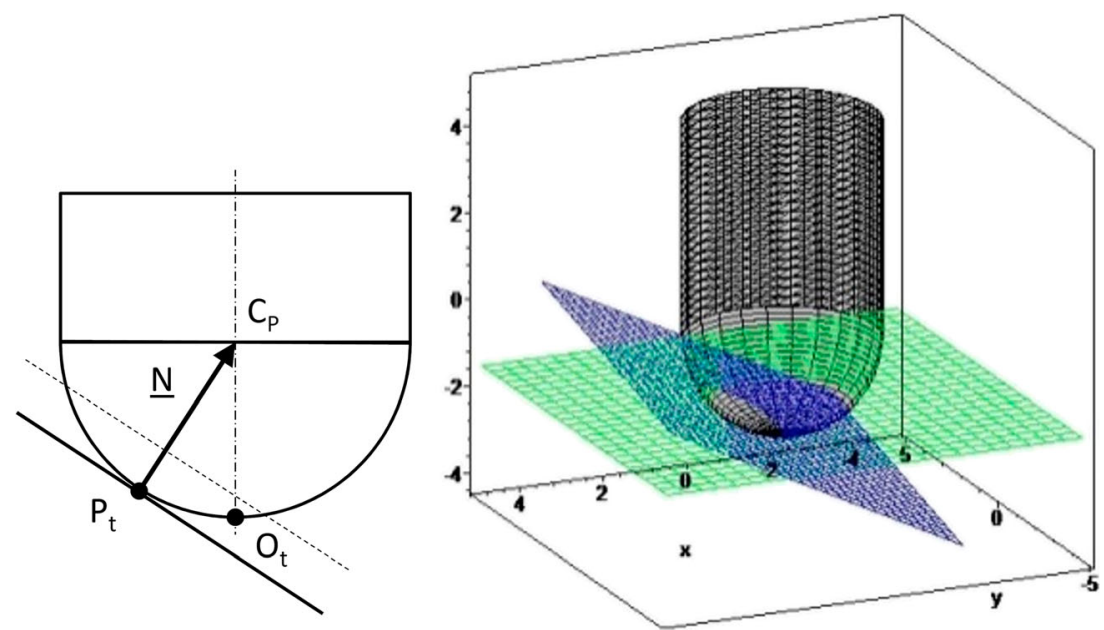

$\overline{\overline{\mathrm{Tr}}}=\overline{\overline{\mathrm{F}_{2}}} \cdot\left(\overline{\overline{\mathrm{T}_{2}}} \cdot\left(\overline{\overline{\mathrm{F}_{1}}} \cdot \overline{\overline{\mathrm{T}_{1}}}\right)\right)$

Applying the transformation on the contact circle, the $\underline{\mathrm{Cr}}^{\mathrm{T}}$ eff describes the contact circle in a general case.

$\overline{\mathrm{C}_{\mathrm{eff}}^{\mathrm{T}}}=\overline{\overline{\mathrm{Tr}}} \cdot \overline{\mathrm{Cr}_{\mathrm{eff}}}$

Figure 6 shows a general example. The actual working diameter is the distance between the centre of the cutting tool and the contact circle. This distance depends on the direction of the milling and the direction of the scanning (feed).

\section{Determining the extreme points of contact curve}

Two points can be defined on the transformed circle where the angle of the tangent line in the $x-y$ plane $(\gamma)$ is equal to the
Fig. 5 Orientation of the surface normal vector
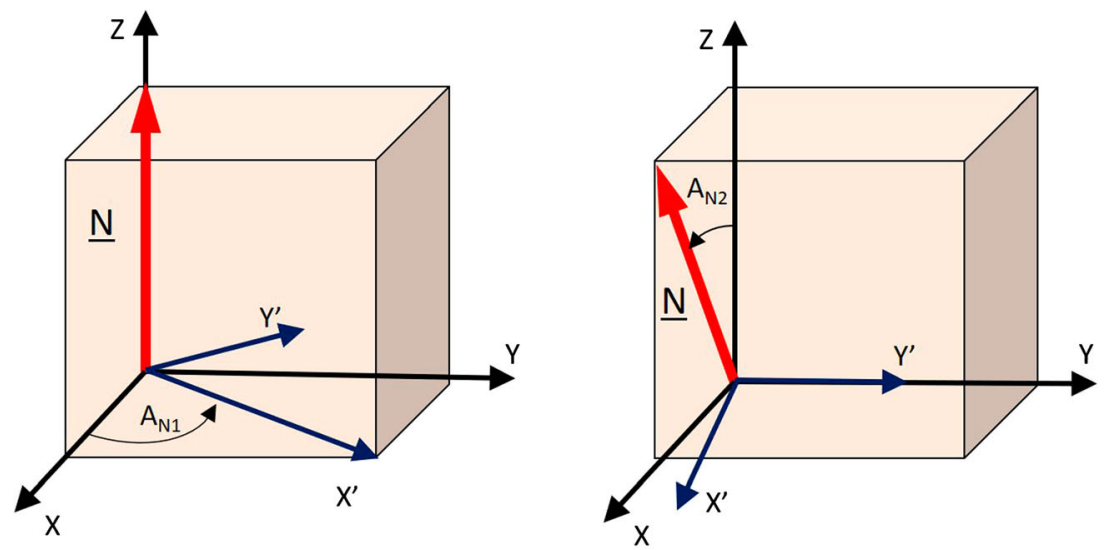

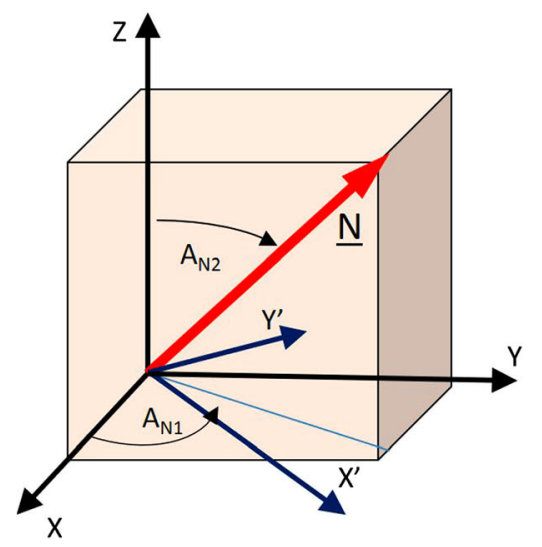




\section{|Front view (X-Z)}

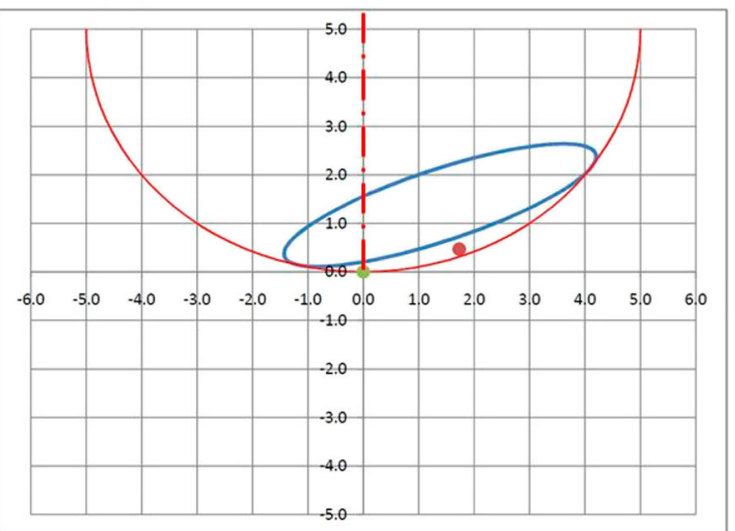

|Top view (X-Y)

ITop view (X.Y)

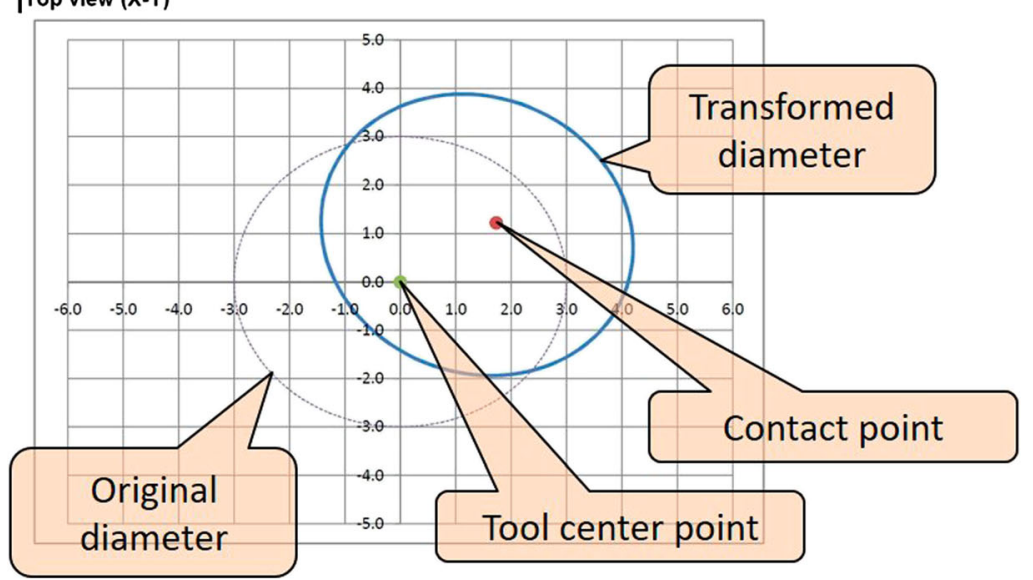

Fig. 6 An example - 3 projected views of the ball-end cutter and the transformed circle

direction angle of the milling path $(A)$. Generally, the tangent line is defined by the first differential of the curve:

$\frac{\mathrm{d}}{\mathrm{dt}} \overline{\mathrm{Cr}}_{\mathrm{eff}}^{\mathrm{T}}=\left[\begin{array}{c}-2 \pi \cdot \cos \left(\mathrm{A}_{\mathrm{N} 1}\right) \cdot \cos \left(\mathrm{A}_{\mathrm{N} 2}\right) \cdot \mathrm{R}_{\mathrm{eff}} \cdot \sin (2 \pi \mathrm{t})-2 \pi \cdot \sin \left(\mathrm{A}_{\mathrm{N} 1}\right) \cdot \mathrm{R}_{\mathrm{eff}} \cdot \cos (2 \pi \mathrm{t}) \\ -2 \pi \cdot \sin \left(\mathrm{A}_{\mathrm{N} 1}\right) \cdot \cos \left(\mathrm{A}_{\mathrm{N} 2}\right) \cdot \mathrm{R}_{\mathrm{eff}} \cdot \sin (2 \pi \mathrm{t})+2 \pi \cdot \cos \left(\mathrm{A}_{\mathrm{N} 1}\right) \cdot \mathrm{R}_{\mathrm{eff}} \cdot \cos (2 \pi \mathrm{t}) \\ -2 \pi \cdot \sin \left(\mathrm{A}_{\mathrm{N} 2}\right) \cdot \mathrm{R}_{\mathrm{eff}} \cdot \sin (2 \pi \mathrm{t}) \\ 1\end{array}\right]$

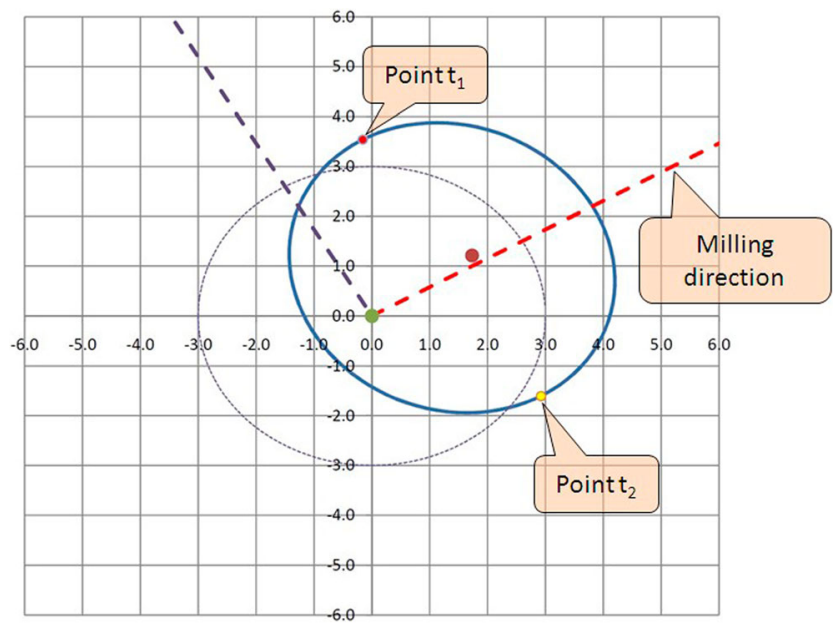

Fig. 7 Tangential points on the transformed curve
|Right view (Y-Z)

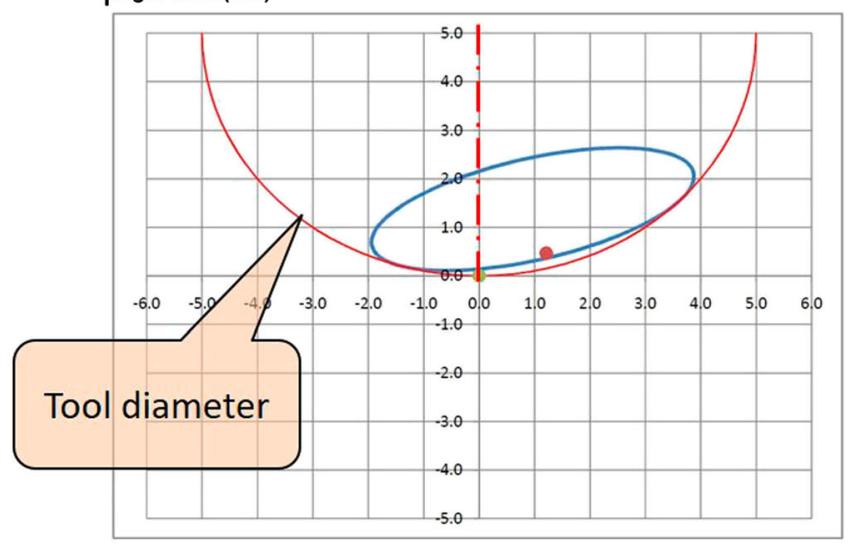




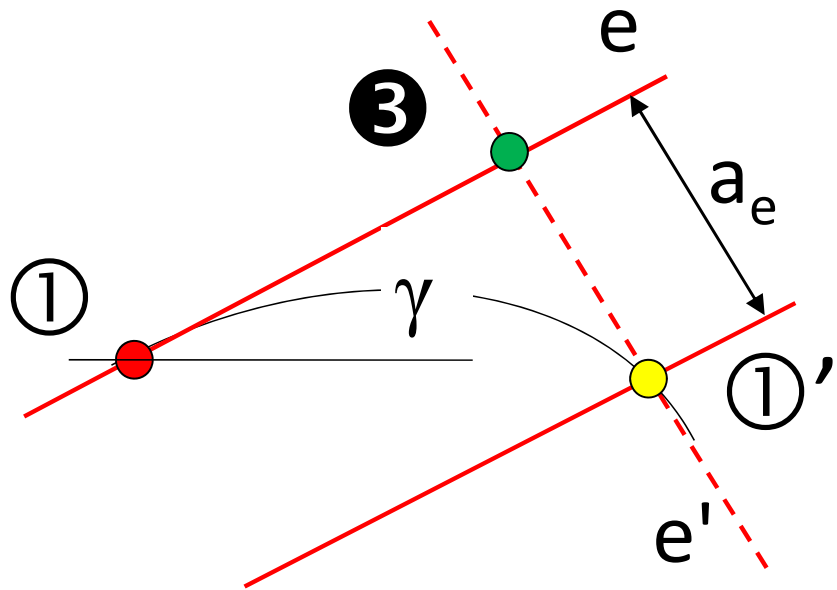

Fig. 9 Parallel offset of the tangent line

simplifying the equation:

$\tan (\gamma(\mathrm{t}))=\frac{\sin \left(\mathrm{A}_{\mathrm{N} 1}\right) \cdot \cos \left(\mathrm{A}_{\mathrm{N} 2}\right) \cdot \sin (2 \pi \mathrm{t})-\cos \left(\mathrm{A}_{\mathrm{N} 1}\right) \cdot \cos (2 \pi \mathrm{t})}{\cos \left(\mathrm{A}_{\mathrm{N} 1}\right) \cdot \cos \left(\mathrm{A}_{\mathrm{N} 2}\right) \cdot \sin (2 \pi \mathrm{t})+\sin \left(\mathrm{A}_{\mathrm{N} 1}\right) \cdot \cos (2 \pi \mathrm{t})}$

according to the original criterion, the specific values of $t$ that defines the two points (Fig. 7) on the curve are determined by $t_{1}$ and $t_{2}$ parameters, where:

$\gamma(\mathrm{t})=A \Rightarrow \mathrm{t} 1 ; \mathrm{t} 2$

The $t_{1}$ and $t_{2}$ parameters define the location of the intersection points on the curve, which is the possible milling diameter. There are two of these points, because these points depend on the scanning (feed) direction. $(t=[0,1])$. The $t$ parameters can be determined by iteration.

The distance of the tool centre and the extreme points of the contact curve define the effective diameter, where the tangent angel $(\gamma)$, is equal to the angle of the milling direction $(A)$.

During the surface milling, there is another extreme point, which is defined by the step-over parameter $\left(a_{e}\right)$. In the case of down-milling, the cutting process starts at point 1 " and ends at point 1 . In the case of up-milling, the cutting cycle starts at point 1 and ends at point $1^{\prime}$. The positions of points $1^{\prime}$ and $1^{\prime \prime}$ depend on the stepover parameter of the tool path (Fig. 8).

Point 3 (Fig. 9) is the intersection point of the tangent line in point $1(e)$ and the perpendicular line from the point $1^{\prime}$ to the line $(e ')$. The distance between the point 3 and point $1^{\prime}$ should be equal to the step over distance $\left(a_{e}\right)$ in the $x-y$ plane. For the step-over distance, the tangent $(e)$ has to be translated by the distance of $a_{e}$ perpendicular to the milling direction. The intersections of this line with the transformed circle mark out the two extreme points $\left(1^{\prime}, 1^{\prime \prime}\right)$.

Determining parameter $t$, which defines the point $1^{\prime}$ in $\underline{\mathrm{Cr}}^{\mathrm{T}}$ eff, when

$d_{1^{\prime}-3}=a_{e}$
Fig. 10 Four boundary points: of chip removal (1', 1", 2', 2")

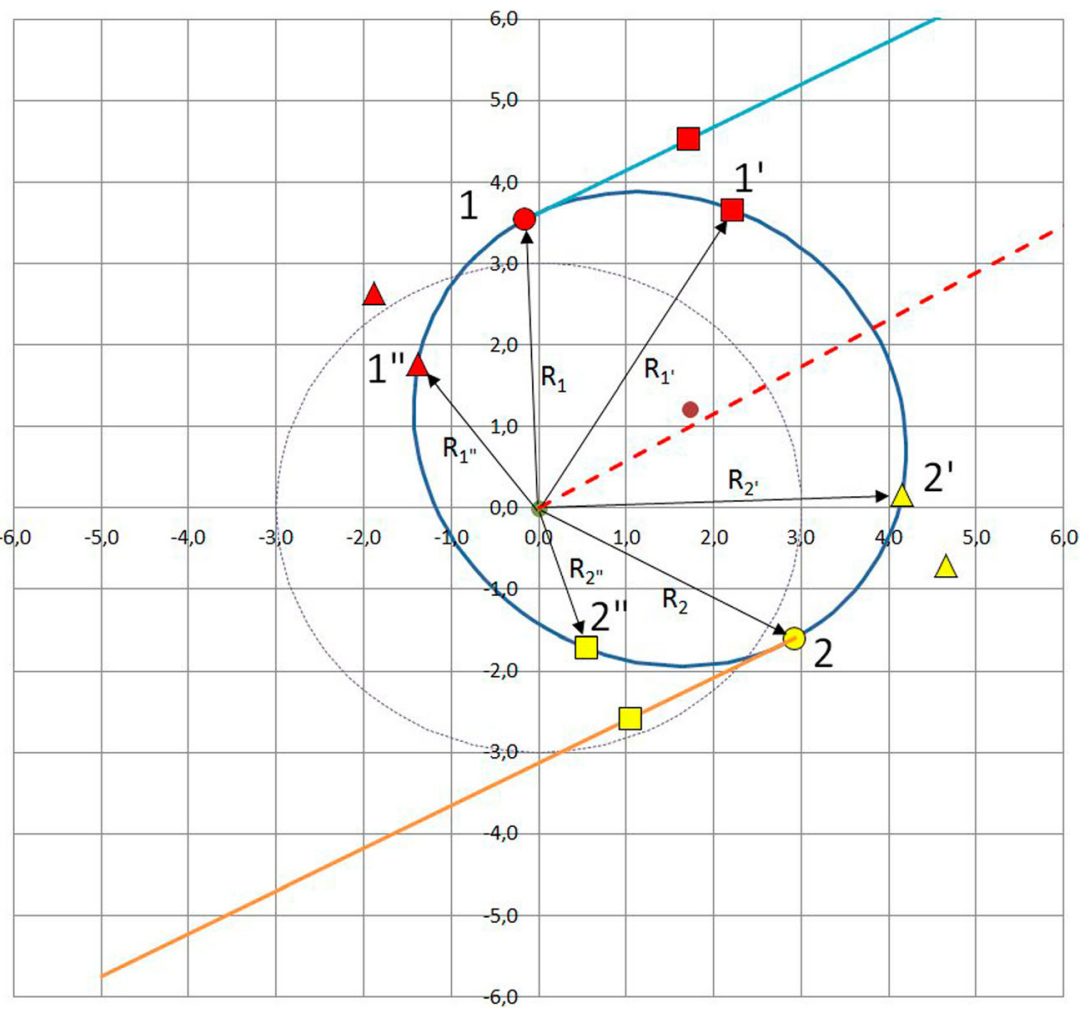


The distance between point $1^{\prime}$ and point 3 is:

$d_{1^{\prime}-3}=\sqrt{\left(x_{3}-x_{1^{\prime}}\right)^{2}+\left(y_{3}-y_{1^{\prime}}\right)^{2}}=a e$

Four points ( 2 per side) are generated according to the milling direction (Fig. 10).

\section{Case studies}

In the next section, three examples are presented in order to demonstrate the importance of the changing of the working diameter and its effect on the cutting speed.

The first example shows the changing of the effective diameter and the cutting speed. In the presented case, the tool diameter is $10 \mathrm{~mm}$, the tool radius is $5 \mathrm{~mm}$, the depth of cut and the width of cut is $1 \mathrm{~mm}$, the cutting speed is $120 \mathrm{~m} / \mathrm{min}$ and the spindle speed is $3820 \mathrm{1} / \mathrm{min}$. The surface orientation can be described by two angles: $A_{\mathrm{N} 1}=35^{\circ}, A_{\mathrm{N} 2}=25^{\circ}$ and the tool path orientation is $A=30^{\circ}$.

The realised cutting speed is always smaller than the designed one because the working diameter is smaller than the nominal diameter of the tool, thus $85.1 \mathrm{~m} / \mathrm{min}$ or $80 \mathrm{~m} / \mathrm{min}$ instead of $120 \mathrm{~m} / \mathrm{min}$ is realised. Moreover, even this speed is not constant during cutting. Depending on the cutting direction, the cutting starts either at points $1^{\prime} / 2^{\prime}$ or at $1^{\prime \prime} / 2^{\prime \prime}$ and finishes at the point $1 / 2$. Although the rotation of the tool is constant, the cutting speed varies because the working diameter varies between the two points. This difference is between 20 and $42 \%$ according to the chosen parameters (Fig. 11).

If parameters that are more suited for smoothing are chosen (e.g.: $a_{\mathrm{p}}=0.2 \mathrm{~mm} ; a_{\mathrm{e}}=0.1 \mathrm{~mm}$ ), the variation of the working diameter and thus the cutting speed would still be significant (Fig. 12).

The second example presents the changing of the effective diameter in the function of the tool path direction $(A)$. In Fig. 13, four solutions are shown when the following parameters were applied: $D_{\mathrm{c}}=10 \mathrm{~mm} ; a_{\mathrm{p}}=1 \mathrm{~mm} ; a_{\mathrm{e}}=1 \mathrm{~mm}$; $A_{\mathrm{N} 1}=35^{\circ} ; A_{\mathrm{N} 2}=25^{\circ}$.

If different tool path direction is set in the CAM system with a zigzag surface milling strategy: the working diameter and the cutting speed will be different. 1' and 1" (Fig. 10) shows the working diameter in the case of forward and backward motion, when the milling is performed from bottom to top ( $Z+$ direction). The $2^{\prime}$ and 2 " (Fig. 10) shows the values of the diameter in the case of top to down milling (Z-direction).

In the case of the investigated surface inclination, the smallest differences between the two diameters are $A=90^{\circ}\left(1^{\prime}-1^{\prime \prime}\right)$ and $A=0^{\circ}\left(2^{\prime}-2^{\prime \prime}\right)$. The value of the difference and the position of the minimum value depends on the surface inclination $\left(A_{\mathrm{N} 1}, A_{\mathrm{N} 2}\right)$ and also on the cutting parameters $\left(a_{\mathrm{p}}, a_{\mathrm{e}}\right)$.
The third example shows the effect of the changing of the surface orientation to the effective diameter when the following parameters were applied $D_{\mathrm{c}}=10 \mathrm{~mm} ; a_{\mathrm{p}}=1 \mathrm{~mm}$; $a_{\mathrm{e}}=1 \mathrm{~mm}$; the tool path direction is $A=60^{\circ}$, the second component of the surface normal vector is changed $\left(A_{\mathrm{N} 1}=30^{\circ} ; A_{\mathrm{N} 2}=-45^{\circ} \ldots 0^{\circ} \ldots 45^{\circ}\right)$.

If the inclination of the surface is changed (as in freeform surfaces), the working diameter also changes; they are equal only in the case if the plane is perpendicular to the " $Z$ " axis. The bottom to top milling is more favourable, because the difference between the two diameters is smaller (Fig. 14).

\section{Results}

According to the presented method, it can be stated that the working diameter of a ball-end milling tool can be calculated by taking into consideration the parameters of the cutting path (direction and density) and the characteristics of the surface
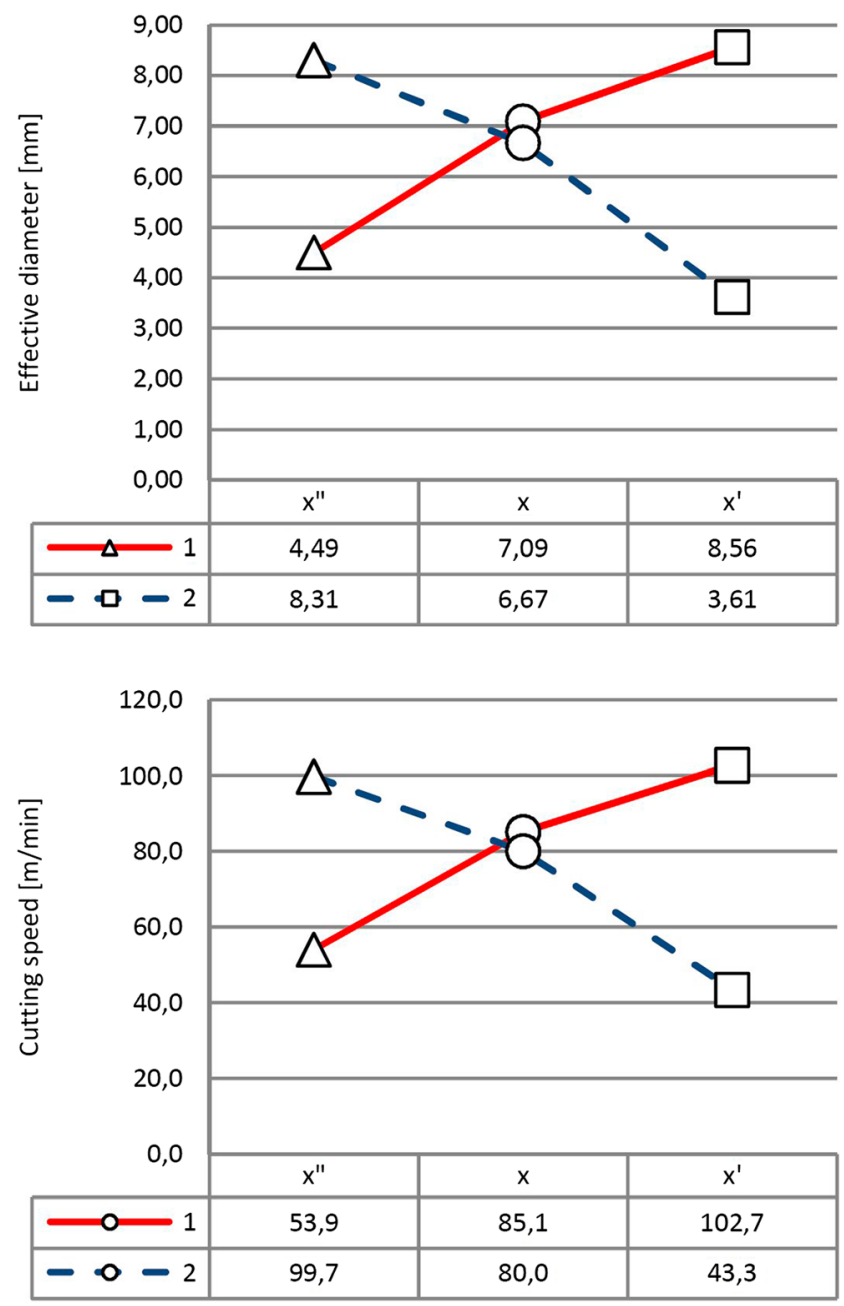

Fig. 11 Effective diameter and cutting speed in the first presented case 

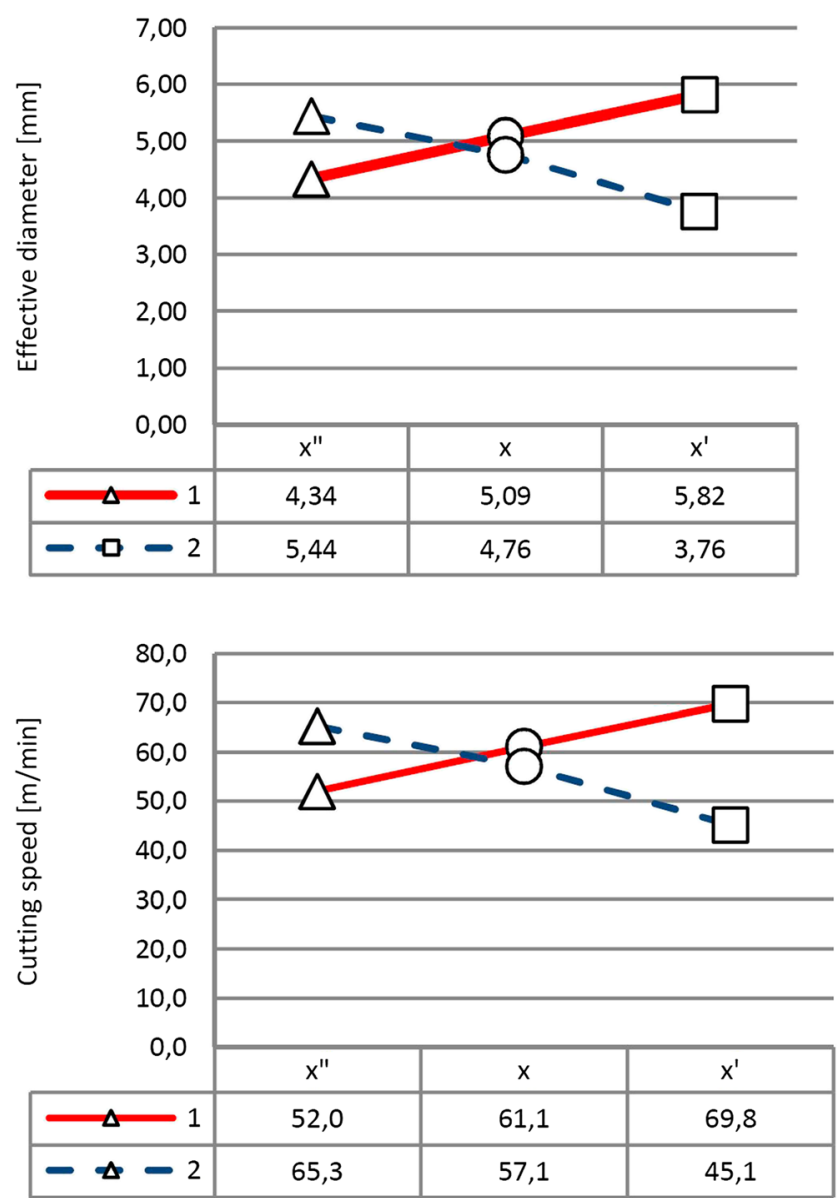

Fig. 12 Effective diameter and cutting speed when $a_{\mathrm{p}}=0.2 \mathrm{~mm} ; a_{\mathrm{e}}=$ $0.1 \mathrm{~mm}$

(surface normals). The results of the calculations provide four solutions. By considering the milling direction and the steps of

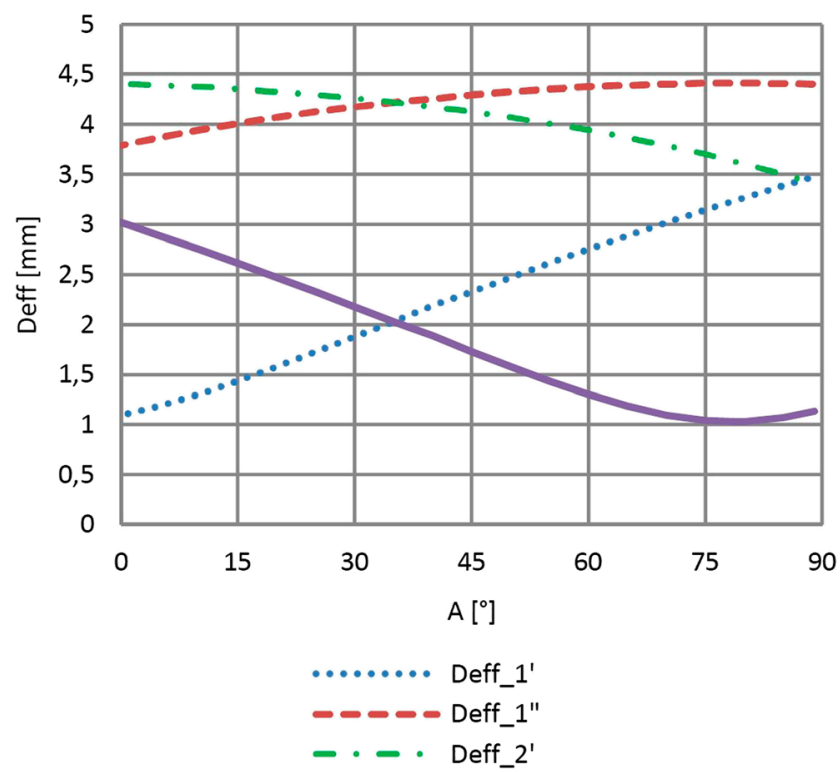

Fig. 13 The changing of the effective diameter in the function of tool path direction

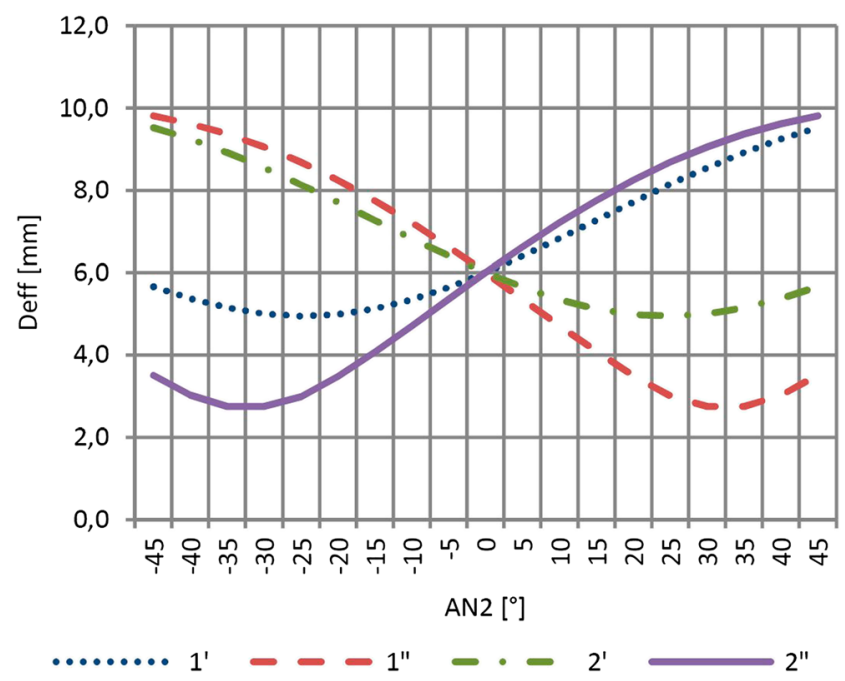

Fig. 14 The changing of the effective diameter in the function of surface inclination

the milling process, only one solution is realised on the course of a given milling path. Along the milling path, provided the direction of the feed does not change $(A)$ meaning that the tool travels in a straight line, the working diameter changes because the surface normal $\left(A_{\mathrm{N} 1}, A_{\mathrm{N} 2}\right)$ changes. It is clear from the results of the sample calculations that the changes are continuous and periodical, but for practical reasons, it is unnecessary to consider the full range. For practical values of each parameter for the examined angles are:

- The value for $A_{\mathrm{N} 1}$ should be in the range between $\pm 180^{\circ}$, this can be reasonable for axisymmetric workpieces (cone, spherical pieces, torus etc.).

- The value for $A_{\mathrm{N} 2}$ can be in the range between $\pm 45^{\circ}$, because the machining of any surfaces steeper than this with a ball-end milling tool is unfavourable.

- Angle $A$ can be any angle between 0 and $360^{\circ}$; however, all the solutions considering angles larger than $180^{\circ}$ is already given in the original solution. These solutions represent the same milling in an opposite direction.

In the development of the theory, the free form surfaces were locally substituted by its tangent plane at the given point.

\section{Conclusion}

The working diameter of a ball-end milling tool is continuously changing during the milling of a free-form surface with a ball-end cutter; thus the actual position of the cutting point on the tool edge is also changing. Together with this parameter, the chip cross section, the cutting force and the effective cutting speed also change. These circumstances and parameters have effect on the micro- and macro precision of the surface too. To minimalize this effect, it is worth considering 


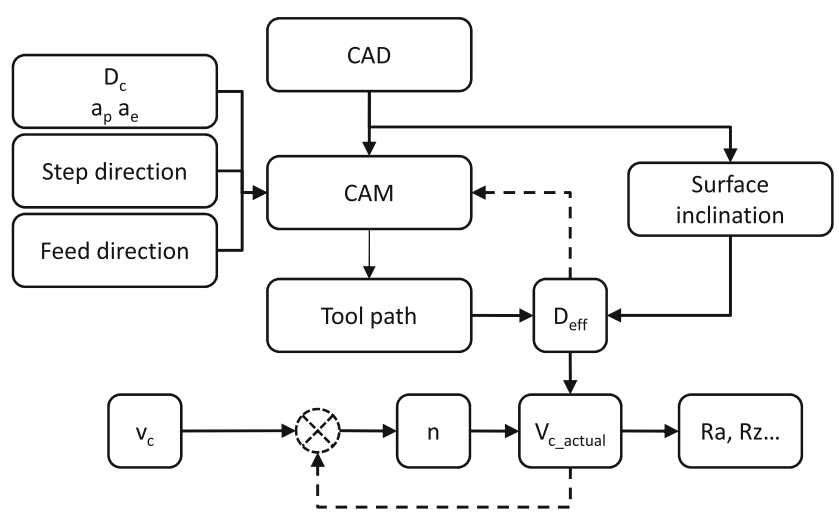

Fig. 15 The proposed concept of tool path planning

keeping the working diameter constant or at a very slightly varying value during the course of tool path planning. A solution for this problem can be the simultaneous 5-axis milling technology. However, this technology is not always applicable or justified for technical and economic reasons; this is why the tree-axis milling will still be a possible solution for a long time to come.

By the proper planning of the milling path, the negative effect of the changing of the working diameter can be considerably reduced. For this, it is necessary to calculate the working diameter at any point of the path on the surface. This is shown in Fig. 15, where this feedback is illustrated with dashed lines.

The two feedbacks imply two different solutions:

1. Taking into consideration the current milling diameter, the milling speed can be varied at each point to keep the cutting speed at the same value.

2. A tool path can be created in a CAM system that minimizes the working tool diameter change by selecting the adequate milling direction from point to point on the path.

Since the design of the toolpath has its constraints and limitations, using only this method will not provide a full solution. In the case of rapidly changing surfaces, the speed variations could be too large thus difficult to apply. It could be a good solution of combining the two strategies in order to create a more homogeneous surface for roughness.

Acknowledgements Open access funding provided by Óbuda University (OE).

\section{Appendix 1}

$$
\begin{aligned}
& \overline{\overline{\mathrm{T}_{1}}}=\left[\begin{array}{cccc}
1 & 0 & 0 & 0 \\
0 & 1 & 0 & 0 \\
0 & 0 & 1 & -\mathrm{R} \\
0 & 0 & 0 & 1
\end{array}\right] \\
& \overline{\overline{F_{1}}}=\left[\begin{array}{cccc}
\cos \left(A_{N 2}\right) & 0 & -\sin \left(A_{N 2}\right) & 0 \\
0 & 1 & 0 & 0 \\
\sin \left(A_{N 2}\right) & 0 & \cos \left(A_{N 2}\right) & 0 \\
0 & 0 & 0 & 1
\end{array}\right] \\
& \overline{\overline{T_{2}}}=\left[\begin{array}{cccc}
1 & 0 & 0 & 0 \\
0 & 1 & 0 & 0 \\
0 & 0 & 1 & R \\
0 & 0 & 0 & 1
\end{array}\right] \\
& \overline{\overline{F_{2}}}=\left[\begin{array}{cccc}
\cos \left(A_{N 1}\right) & -\sin \left(A_{N 1}\right) & 0 & 0 \\
\sin \left(A_{N 1}\right) & \cos \left(A_{N 1}\right) & 0 & 0 \\
0 & 0 & 1 & 0 \\
0 & 0 & 0 & 1
\end{array}\right] \\
& \overline{\overline{T r}}=\overline{\overline{F_{2}}} \cdot\left(\overline{\overline{T_{2}}} \cdot\left(\overline{\overline{F_{1}}} \cdot \overline{\overline{T_{1}}}\right)\right) \\
& \overline{\overline{F_{1}}} \cdot \overline{\overline{T_{1}}}=\left[\begin{array}{cccc}
\cos \left(A_{N 2}\right) & 0 & -\sin \left(A_{N 2}\right) & 0 \\
0 & 1 & 0 & 0 \\
\sin \left(A_{N 2}\right) & 0 & \cos \left(A_{N 2}\right) & 0 \\
0 & 0 & 0 & 1
\end{array}\right] \cdot\left[\begin{array}{cccc}
1 & 0 & 0 & 0 \\
0 & 1 & 0 & 0 \\
0 & 0 & 1 & -R \\
0 & 0 & 0 & 1
\end{array}\right] \\
& \overline{\overline{\mathrm{F}_{1}}} \overline{\overline{\mathrm{T}_{1}}}=\left[\begin{array}{cccc}
\cos \left(\mathrm{A}_{\mathrm{N} 2}\right) & 0 & -\sin \left(\mathrm{A}_{\mathrm{N} 2}\right) & \mathrm{R} \cdot \sin \left(\mathrm{A}_{\mathrm{N} 2}\right) \\
0 & 1 & 0 & 0 \\
\sin \left(\mathrm{A}_{\mathrm{N} 2}\right) & 0 & \cos \left(\mathrm{A}_{\mathrm{N} 2}\right) & -\mathrm{R} \cdot \cos \left(\mathrm{A}_{\mathrm{N} 2}\right) \\
0 & 0 & 0 & 1
\end{array}\right]
\end{aligned}
$$




$$
\overline{\overline{F_{2}}} \cdot\left(\overline{\overline{T_{2}}} \cdot\left(\overline{\overline{F_{1}}} \cdot \overline{\overline{T_{1}}}\right)\right)=\left[\begin{array}{cccc}
\cos \left(A_{N 1}\right) & -\sin \left(A_{N 1}\right) & 0 & 0 \\
\sin \left(A_{N 1}\right) & \cos \left(A_{N 1}\right) & 0 & 0 \\
0 & 0 & 1 & 0 \\
0 & 0 & 0 & 1
\end{array}\right] \cdot\left[\begin{array}{cccc}
\cos \left(A_{N 2}\right) & 0 & -\sin \left(A_{N 2}\right) & R \cdot \sin \left(A_{N 2}\right) \\
0 & 1 & 0 & 0 \\
\sin \left(A_{N 2}\right) & 0 & \cos \left(A_{N 2}\right) & R \cdot\left(1-\cos \left(A_{N 2}\right)\right) \\
0 & 0 & 0 & 1
\end{array}\right]
$$

$\overline{\overline{T r}}=\left[\begin{array}{cccc}\cos \left(A_{N 1}\right) \cdot \cos \left(A_{N 2}\right) & -\sin \left(A_{N 1}\right) & -\cos \left(A_{N 1}\right) \cdot \sin \left(A_{N 2}\right) & R \cdot \cos \left(A_{N 1}\right) \cdot \sin \left(A_{N 2}\right) \\ \sin \left(A_{N 1}\right) \cdot \cos \left(A_{N 2}\right) 0 & \cos \left(A_{N 1}\right) & -\sin \left(A_{N 1}\right) \cdot \sin \left(A_{N 2}\right) & -R \cdot \cos \left(A_{N 1}\right) \cdot \sin \left(A_{N 2}\right) \\ \sin \left(A_{N 2}\right) & 0 & \cos \left(A_{N 2}\right) & R \cdot\left(1-\cos \left(A_{N 2}\right)\right) \\ 0 & 0 & 0 & 1\end{array}\right]$

$\overline{C_{e f f}^{T}}=\overline{\overline{T r}} \cdot \overline{C r_{e f f}}=\left[\begin{array}{cccc}\cos \left(A_{N 1}\right) \cdot \cos \left(A_{N 2}\right) & -\sin \left(A_{N 1}\right) & -\cos \left(A_{N 1}\right) \cdot \sin \left(A_{N 2}\right) & R \cdot \cos \left(A_{N 1}\right) \cdot \sin \left(A_{N 2}\right) \\ \sin \left(A_{N 1}\right) \cdot \cos \left(A_{N 2}\right) & \cos \left(A_{N 1}\right) & -\sin \left(A_{N 1}\right) \cdot \sin \left(A_{N 2}\right) & -R \cdot \cos \left(A_{N 1}\right) \cdot \sin \left(A_{N 2}\right) \\ \sin \left(A_{N 2}\right) & 0 & \cos \left(A_{N 2}\right) & R \cdot\left(1-\cos \left(A_{N 2}\right)\right) \\ 0 & 0 & 0 & 1\end{array}\right] \cdot\left[\begin{array}{c}R_{e f f} \cdot \cos (2 \pi t) \\ R_{e f f} \cdot \sin (2 \pi t) \\ a_{p} \\ 1\end{array}\right]$

$\overline{C_{e f f}^{T}}=\left[\begin{array}{c}\cos \left(A_{N 1}\right) \cdot \cos \left(A_{N 2}\right) \cdot R_{\text {eff }} \cdot \cos (2 \pi t)-\sin \left(A_{N 1}\right) \cdot R_{\text {eff }} \cdot \sin (2 \pi t)-\cos \left(A_{N 1}\right) \cdot \sin \left(A_{N 2}\right) \cdot a_{p}+R \cdot \cos \left(A_{N 1}\right) \cdot \sin \left(A_{N 2}\right) \\ \sin \left(A_{N 1}\right) \cdot \cos \left(A_{N 2}\right) \cdot R_{e f f} \cdot \cos (2 \pi t)+\cos \left(A_{N 1}\right) \cdot R_{e f f} \cdot \sin (2 \pi t)-\sin \left(A_{N 1}\right) \cdot \sin \left(A_{N 2}\right) \cdot a_{p}-R \cdot \cos \left(A_{N 1}\right) \cdot \sin \left(A_{N 2}\right) \\ \sin \left(A_{N 2}\right) \cdot R_{e f f} \cdot \cos (2 \pi t)+\cos \left(A_{N 2}\right) \cdot a_{p}+R \cdot\left(1-\cos \left(A_{N 2}\right)\right) \\ 1\end{array}\right]$

$\frac{d}{d t} \overline{C r}_{e f f}^{T}=\left[\begin{array}{c}-2 \pi \cdot \cos \left(A_{N 1}\right) \cdot \cos \left(A_{N 2}\right) \cdot R_{\text {eff }} \cdot \sin (2 \pi t)-2 \pi \cdot \sin \left(A_{N 1}\right) \cdot R_{\text {eff }} \cdot \cos (2 \pi t) \\ -2 \pi \cdot \sin \left(A_{N 1}\right) \cdot \cos \left(A_{N 2}\right) \cdot R_{e f f} \cdot \sin (2 \pi t)+2 \pi \cdot \cos \left(A_{N 1}\right) \cdot R_{e f f} \cdot \cos (2 \pi t) \\ -2 \pi \cdot \sin \left(A_{N 2}\right) \cdot R_{e f f} \cdot \sin (2 \pi t) \\ 1\end{array}\right]$

$\tan (\gamma(t))=\frac{-2 \pi \cdot \sin \left(A_{N 1}\right) \cdot \cos \left(A_{N 2}\right) \cdot R_{e f f} \cdot \sin (2 \pi t)+2 \pi \cdot \cos \left(A_{N 1}\right) \cdot R_{e f f} \cdot \cos (2 \pi t)}{-2 \pi \cdot \cos \left(A_{N 1}\right) \cdot \cos \left(A_{N 2}\right) \cdot R_{e f f} \cdot \sin (2 \pi t)-2 \pi \cdot \sin \left(A_{N 1}\right) \cdot R_{e f f} \cdot \cos (2 \pi t)}$

$\tan (\gamma(t))=\frac{\sin \left(A_{N 1}\right) \cdot \cos \left(A_{N 2}\right) \cdot \sin (2 \pi t)-\cos \left(A_{N 1}\right) \cdot \cos (2 \pi t)}{\cos \left(A_{N 1}\right) \cdot \cos \left(A_{N 2}\right) \cdot \sin (2 \pi t)+\sin \left(A_{N 1}\right) \cdot \cos (2 \pi t)}$

$\gamma(t)=A$

\section{Appendix 2}

e:

$$
\begin{aligned}
& \left(\mathrm{y}-\mathrm{y}_{1}\right)=\mathrm{m}_{1} \cdot\left(\mathrm{x}-\mathrm{x}_{1}\right) \\
& \mathrm{m}_{1}=\operatorname{tg}(\gamma) \\
& \mathrm{y}=\mathrm{m}_{1} \cdot\left(\mathrm{x}-\mathrm{x}_{1}\right)+\mathrm{y}_{1}
\end{aligned}
$$




$$
\text { e': }
$$

$$
\begin{aligned}
& \left(\mathrm{y}-\mathrm{y}_{1^{\prime}}\right)=\mathrm{m}_{1^{\prime}} \cdot\left(\mathrm{x}-\mathrm{x}_{1^{\prime}}\right) \\
& \mathrm{m}_{1^{\prime}}=\operatorname{tg}\left(\gamma+\frac{\pi}{2}\right) \\
& \mathrm{y}=\mathrm{m}_{1^{\prime}} \cdot\left(\mathrm{x}-\mathrm{x}_{1^{\prime}}\right)+\mathrm{y}_{1^{\prime}} \\
& e \times e^{\prime}
\end{aligned}
$$$$
\mathrm{m}_{1} \cdot\left(\mathrm{x}_{3}-\mathrm{x}_{1}\right)+\mathrm{y}_{1}=\mathrm{m}_{1^{\prime}} \cdot\left(\mathrm{x}_{3}-\mathrm{x}_{1^{\prime}}\right)+\mathrm{y}_{1^{\prime}}
$$$$
\mathrm{m}_{1} \cdot \mathrm{x}_{3}-\mathrm{m}_{1} \cdot \mathrm{x}_{1}+\mathrm{y}_{1}=\mathrm{m}_{1^{\prime}} \cdot \mathrm{x}_{3}-\mathrm{m}_{1^{\prime}} \cdot \mathrm{x}_{1^{\prime}}+\mathrm{y}_{1^{\prime}}
$$$$
\mathrm{x}_{3} \cdot\left(\mathrm{m}_{1}-\mathrm{m}_{1^{\prime}}\right)=\mathrm{y}_{1^{\prime}}-\mathrm{y}_{1}+\mathrm{m}_{1} \cdot \mathrm{x}_{1}-\mathrm{m}_{1^{\prime}} \cdot \mathrm{x}_{1^{\prime}}
$$$$
\mathrm{x}_{3}=\frac{\mathrm{y}_{1^{\prime}}-\mathrm{y}_{1}+\mathrm{m}_{1} \cdot \mathrm{x}_{1}-\mathrm{m}_{1^{\prime}} \cdot \mathrm{x}_{1^{\prime}}}{\left(\mathrm{m}_{1}-\mathrm{m}_{1^{\prime}}\right)}
$$$$
\mathrm{y}_{3}=\mathrm{m}_{1} \cdot\left(\mathrm{x}-\mathrm{x}_{1}\right)+\mathrm{y}_{1}
$$$$
\mathrm{d}_{1^{\prime}-3}=\sqrt{\left(\mathrm{x}_{3}-\mathrm{x}_{1^{\prime}}\right)^{2}+\left(\mathrm{y}_{3}-\mathrm{y}_{1^{\prime}}\right)^{2}}
$$

Open Access This article is distributed under the terms of the Creative Commons Attribution 4.0 International License (http:// creativecommons.org/licenses/by/4.0/), which permits unrestricted use, distribution, and reproduction in any medium, provided you give appropriate credit to the original author(s) and the source, provide a link to the Creative Commons license, and indicate if changes were made.

\section{References}

1. Fan J (2014) Cutting speed modelling in ball nose milling applications. Int J Adv Manuf Technol 73:161-171

2. de Souza AF, Diniz AE, Rodrigues AR, Coelho RT (2014) Investigating the cutting phenomena in free-form milling using a ball-end cutting tool for die and mold manufacturing. Int $\mathrm{J}$ Adv Manuf Technol 71:1565-1577

3. Wojciechowski S, Twardowski P, Wieczorowski M (2014) Surface texture analysis after ball end milling with various surface inclination of hardened steel. Metrol Meas Syst 21(1):145-156

4. Vopát T, Peterka J, Šimna V, Kuruc M (2015) The influence of different types of copy milling on the surface roughness and tool life of end mills. Procedia Engineering 100:868-876

5. Wojciechowski S, Chwalczuk T, Twardowski P, Krolczyk GM (2015) Modelling of cutter displacements during ball end milling of inclined surfaces. Arch Civil Mech Eng 15:798-805

6. Vyboishchik AV (2016) Modelling topology of freeform surfaces with ball-end milling. Procedia Engineering 150:761-767
7. J. Beňo; I. Manková; P. Ižol; M. Vrabel' (2016) An approach to the evaluation of multivariate data during ball end milling free-form surface fragments; Measurement 84:7-20

8. Pena AE, Anania FD, Zapciu M (2015) Research concerning optimum cutting parameters according with tool path strategy for finishing procedures. Mater Sci Eng 95:012020

9. de Souza AF, Machado A, Beckert SF, Diniz AE (2014) Evaluating the roughness according to the tool path strategy when milling free form surfaces for mold application. Proc CIRP 14:188-193

10. Sales HR, Amirabadi H, Hosseinabadi HN, Bagheri MR (2016) Experimental study of tool path strategies for three and five axes milling along with feed rate optimization. Indian J Sci Technol 9(43)

11. Ižol P, Tomáš M, Beňo J (2016) Milling strategies evaluation when simulating the forming dies' functional surfaces production. Open Eng 6:98-105

12. Pena AE, Anania FD, Mohora C (2017) Method for optimum calculus of machining parameters according to tool trajectories type based on milling process simulation. Tehnički vjesnik 24(2):385-389

13. Redonnet J-M, Vázquez AG, Michel AT, Segonds S (2016) Optimisation of free-form surface machining using parallel planes strategy and torus milling cutter. Proc Inst Mech Eng B J Eng Manuf 0954405416640175

14. Zhang Q, Zhang S, Shi W (2018) Modeling of surface topography based on relationship between feed per tooth and radial depth of cut in ball-end milling of AISI H13 steel. J Adv Manuf Technol 95(912):4199-4209

15. Yang L, Wu S, Liu X, Liu Z, Zhu M, Li Z (2018) The effect of characteristics of free-form surface on the machined surface topography in milling of panel mold. Int J Adv Manuf Technol 98:151-163

16. Xu J, Zhang H, Sun Y (2018) Swept surface-based approach to simulating surface topography in ball-end milling. Int $\mathrm{J}$ Adv Manuf Technol 98:107-118

17. Liu X, Li Y, Li Q (2018) A region-based 3 + 2-axis machining toolpath generation method for freeform surface. Adv Manuf Technol 97(1-4):1149-1163

18. Mikó B, Beno J (2014) Effect of the working diameter to the surface quality in free-form surface milling. Key Eng Mat 581:372-377

19. Beno J, Mikó B, Mankova I, Vrabel M (2014) Influence of tool path orientation on the surface roughness when end ball milling rounded surfaces. Key Eng Mater 581:329-334

20. Mikó B, Baranyai G (2015) The effect of milling direction to surface quality when free form surface finishing. Proc Dev Mach Technol 5:62-76

Publisher's note Springer Nature remains neutral with regard to jurisdictional claims in published maps and institutional affiliations. 